\title{
Variações sobre o tema Eurídice
}

\section{Variations on the theme Eurydice}

Aimée G. Bolaños ${ }^{1}$

Submetido em 20 e aprovado em 31 de dezembro de 2020.

Resumo: A figura mítica de Eurídice ressurge na poesia contemporânea de autoria feminina com renovas significações. O presente artigo lê textos poéticos de Margaret Atwood, Juana Rosa Pita, Gwendolyn MacEwen, Sophia de Mello Breyner Andresen, explicitamente referidos ou vinculados de modo mais livremente alusivo a sua figura, entrelaçando a escritura reflexiva e a experiência criativa ficcional como parte de um projeto autoral em desenvolvimento. Estas notas vão acompanhadas de um conjunto de poemas que interpretam variações sobre o tema de Eurídice.

Palavras-chaves: identidade narrativa, Eurídice, poesia contemporânea, autoria feminina, autopoética.

Abstract: The mythical figure of Eurydice resurfaces in contemporary poetry of feminine authorship with renewed significances This article reads poetic texts by Margaret Atwood, Juana Rosa Pita, Gwendolyn MacEwen, Sophia de Mello Breyner Andresen, explicitly referred to he figure or linked in a more freely way, intertwining reflective writing and fictional creative experience as part of an authorial project under development. These notes are accompanied by a set of poems that interpret variation on the theme of Eurydice.

Keywords: narrative identity, Eurydice, contemporary poetry, female authorship, autopoetic.

Mas espera-me:

Pois por mais longos que sejam os caminhos

Eu regresso.

Sophia de Mello Breyner Andresen

Gostaria de abrir com uma pergunta feita a mim mesma e aos leitores deste texto: Por que a figura mítica de Eurídice atrai de maneira poderosa e recorrente? Ela se faz visível e invisível, aparece e se desvanece, fica no silêncio e fala. Eurídice não deixa de incitar, surpreender, assombrar. É possível imaginá-la de diferentes maneiras, mas 
algo inalterável a identifica, embora nem sempre seja explícito. Como sabemos, tem sido objeto e sujeito de diálogos memoráveis na literatura e nas artes visuais. Sobretudo, escritoras contemporâneas se reconhecem nela das mais variadas formas ao configurá-la desde dentro - assunto que motiva estas notas -, integrando vivencias e convicções sobre a existência social da mulher. Eurídice é vivida e revivida como metáfora viva na sua dramática intimidade de tão fulgurantes sentidos simbólicos.

Há pouco tempo foi publicado um instigante romance, $A$ vida invisível de Eurídice Gusmão (2016), de Martha Batalha. Sua narrativa deu origem a um filme, A vida invisivel (2019), dirigido por Karim Aïnouz. Os dois privilegiam no título o motivo da invisibilidade da mulher condenada ao submundo da irrealização, tema de rico apelo no contexto da crítica feminista. Pensando em filmes, impossível esquecer Orfeu negro (1959), dirigido por Marcel Camus, que vi em Cuba no seu momento de estréia, obra memorável além das polêmicas que suscitou. Esta versão foi vaticínio, então inexplicável, se bem marcante ao mostrar um universo que reconheci como meu e de outro (terceiro) mundo. Orfeu (1999), de Cacá Diegues (1999), surgiria depois. Ambos os filmes baseados livremente na peça de Vinicius de Moraes Orfeu da Conceição (1956). No âmbito da favela e o carnaval, o mito de tanta ressonância na história da literatura e da arte será redimensionando. O autor declara como esta obra permitiu "sem esforço, num simples relampejar do pensamento, sentir no divino músico da Trácia a natureza de um dos divinos músicos de morro carioca" (MORAES, 1956, p. 14). Orfeu ocupa o primeiro plano, Eurídice deverá esperar.

Sem deixar de me interessar por essas versões fílmicas que privilegiam a perspectiva de Orfeu, se bem que os dois amantes estejam atrelados na trama mítica ${ }^{2}$, comecei a procurar outras representações de Eurídice na poesia contemporânea de autoria feminina. Buscava Eurídice como alicerce e foco da trama, recontado o mito.

A poesia de Margaret Atwood foi ponto de partida pela proposta gendrada e a trama original. Escrevi um artigo (2004)3 , onde examino os poemas "Eurydice" e "Orpheus (1)" de Interlunar (1984). Aprofundando no tema sobre a base dessa primeira aproximação, surgiu "Interpretaciones de Eurídice" (2007)4. Nesse ensaio leio comparativamente Eurídice en la fuente (1979), de Juana Rosa Pita, e os poemas de Margaret Atwood em que Eurídice está presente como figura dominante. 
Então, este raconto não é gratuito. Supõe a busca, que dura anos, de outros entendimentos e modos de configurar heterodoxos, talvez baixo continuo na tentativa de ganhar consciência, na ordem teórica, em relação a uma autopoética ${ }^{5}$ em formação. Constitui, portanto, um catálogo pessoal e limitado considerado em relação à abrangência do assunto, mas motivação principal, explícita ou subjacente, de uma experiência autoral; o que em poesia, como na vida, não resulta menos significativo e desafiador.

\section{Eurídice nas escrituras reflexivas: o laboratório de formas}

Nas escrituras reflexivas sobre as poéticas distintivas de Margaret Atwood e Juana Rosa Pita, exploro a composição da identidade narrativa de Eurídice nos termos da teoria de Paul Ricoeur (1996; 2001), a qual toma a narração como modelo heurístico de apreensão do ser-no-mundo. Nesta concepção, a experiência de identidade passa pelo registro textual, implica atos discursivos que se inscrevem no espaço e tempo de si mesmo e dos outros, para configurar existências imaginárias, sensíveis e intelectualizadas, abertas à interpretação em uma dinâmica que vai da vida ao texto, do texto á leitura. Precisamente este vaivém foi meu percurso de leitura-escritura sobre o tema de Eurídice e suas variações.

Focalizado nas dimensões discursivas e compositivas, o conceito de Ricoeur me permitiu explorar de maneira mais atenta à história mítica, a natureza da enunciação, as maneiras de inventar, de fabular a Eurídice que nessas autoras, Atwood e Pita, é um tipo de sujeito pós-metafisico, característico da cultura artística e intelectual da alta modernidade, onde as identidades são tão fluidas e mutantes que desafiam o próprio conceito de identidade. Nos textos das duas poetas trata-se de uma figura mítica mulher, narrativizada em episódios de vida e na emergência de si. Sujeito poético, nem homogêneo, nem autotélico, mas relacional, trazendo consigo a alteridade que também identifica a esta versões da Eurídice mítica.

A identidade narrativa me permitiu vislumbrar formas do figurável, ao examinar as fronteiras cada vez más flexíveis entre mundo e figuração poética. Estava à procura de modelos na ficção, nunca em oposição ao mundo da vida, mas altamente imaginativos, de projeções metafóricas e simbólicas. 
A proposta de ontologia hermenêutica de Ricoeur resultou-me, ademais, muito promissória na indagação do oficio leitor na criação de sentidos ao instaurar outros horizontes epistemológicos marcadamente de autocognitivos. A identificação com o sujeito Eurídice, fio de trama, faz possível não só a interpretação. O leitor volta-se para si. E era esse meu empenho na escritura: transitar entre interpretação e autointerpretação.

Também Ricoeur levou-me a atualização do conceito aristotélico de mimese, não imitação, senão mediação entre tempo e narrativa e entendimento de mito como "posta em trama", fazer sobre um fazer. Destacaria, neste processo reflexivo, a ideia de mito atrelado a trama, imaginação, composição, representação. A ficção revelava-se "laboratório de formas".

$\mathrm{O}$ conceito de identidade narrativa conduz-me naturalmente à poética e, nesse marco, a investigar os vínculos entre mito e mimese. Focada nas dimensões ontológicas das representações do mitema de Eurídice, avancei em zonas de identidade contraditórias e muito ricas, inseparáveis da experiência das autoras, das leitoras e leitores, todos inscritos na temporalidade histórica que o mito, longe de esvaziar ou abstrair, revela com renovada força.

Na pluralidade de concepções sobre mito, a teoria de Roland Barthes (1980), resulto-me particularmente atrativa, pois estava - estou - lidando com identidades míticas, aquelas nas que autor e leitor exploram a tessitura de uma vida (própria, do outro) em um sistema semiológico de segunda ordem. E chego aqui a o que me resultou fundamental. Para Barthes o mito supõe uma forma ambígua, contraditória, cheia e vazia. Ao deixar atrás sua contingência de letra já estabelecida, longe de esconder suas funções metaficcionais, as exibe, mas os signos não são arbitrários.

Barthes analisa como o mito congela os significados para lançar-los a una semiose sem fim. Interpela a partir de analogias e gera diversas leituras. Lido diacronicamente conserva vestígios das anteriores interpretações; lido em sincronia, oferece uma trama irreal possível. Assim ler literariamente um mito é entrar em uma vasta rede de formas significantes.

Dessa forma aconteceu comigo neste processo, embora muitos significados ainda reclamem interpretação. Tanto Margaret Atwood como Juana Rosa Pita (nascidas em 
1939) concebem Eurídice no espírito libertário dos anos 70-80, concedendo primazia à autopoiese. Assim autogênese e metamorfose, sobre a base do autoconhecimento, estão no centro da busca ontológica que Eurídice representa. Margaret Atwood desestabiliza os estereótipos com a ironia intertextual de seus arquétipos; Juana Rosa Pita trama também uma figura arquetípica, mas a partir de uma memória imaginária que tem um forte vínculo com sua condição transcultural como poeta de uma diáspora.

Ao criar versões, visões, estilos diferençados, as poetas conservam e transformam o mitema em sua relação com o cânone. A identidade de Eurídice, tramada na narração, está referida a uma subjetividade única, possivelmente autoficcional e de projeção simbólica. Nesse espaço intermédio entre historicidade e mito, nesse interstício auto e bio ficcional de tantas potencialidades, resscrevem o mito de Eurídice, focalizando, e gostaria de sublinhá-lo, a figura feminina na sua metamorfose.

Essas ficções de Eurídice, e vale invocar de novo a Ricoeur, revelam a mudaça na coesão de uma vida. A identidade é um si-mismo (ipse), uma estruturação temporal dinâmica que resulta da composição. Atwood e Pita configuram um processo aberto que potencializa zonas de silencio, escuras e luminosas. Pela condição de escritoras de espaços liminares e interstícios, nada é definitivo. Em conseqüência, os níveis de leitura interpretativa são instáveis e fluidos.

Com suas audazes propostas, Pita e Atwood modelam um leitor em movimento que age. Leitor semiótico que se pergunta sobre a composição como forma que significa e, neste caso particularmente interessado na interpretação mítica. Na Eurídice plural da poesia, ao esvaziamento do mito, sucede a plenitude dos sentidos da nova mitificação com suas estratégias intertextuais, transgressivas, de inclusão.

À ortodoxia sucede a proposta heterodoxa: a história já não é contada desde ou por Orfeu. Eurídice consegue deixar o inferno ou quer ficar nele, recodificado como espaço de ressurreição e renascimento, a morte é fecundante, inicio jubiloso, Eurídice/ corpo é vazia, mas Eurídice/sombra, carregando trevas, está plena. Sua metamorfose não é só resistência, mas libertação de uma forma que a aprisionava. Ela está no caminho do encontro consigo, do autoconhecimento e, por tanto, de sua transfiguração. Em termos de poética, poderia se pensar nas trevas luminosas em Margaret Atwood e 
na ascensão à luz em Juana Rosa Pita. Os seus poemas, anábese e catábase ${ }^{6}$ mostram uma poderosa recriação.

\section{A caminho de Eurídice}

Certamente estas versões de Eurídice, e durante um bom tempo as escrituras reflexivas referidas às configurações poéticas, estavam incitando-me a ler a própria vida na tessitura da ficção desde a perspectiva de uma narração clássica situada na temporalidade e no espaço do mito. A experiência vital era desafiada pela forma.

Eis que, quando começo a escrever ficção na poesia, Eurídice aparece em "Despedida de Eurídice" de Las palabras viajeras (2010). Neste livro ensaio variantes da autoficçao - memória, autoconfissão, autorretrato, carta -, assunto que pesquisava no trabalho acadêmico. Desde o princípio foi evidente que bioficção e autoficção se comunicam nas suas estruturas profundas, ainda que essa relação tenha sido escassamente apontada nas teorias das escrituras de si mesmo. Abria-se uma nova perspectiva, tanto na teoria como na ficção.

Conceber Escribas (2013) foi um exercício natural, sem deixar de ser deliberado. No livro desenvolvi essas modalidades genéricas da metaficção nos seus vínculos ostensivos. As vidas imaginárias, uma máscara autorreflexiva; a autoficção, um exercício biográfico voltado para si, de pretensão "realista" ou fantástica. E, em lugar central, a retomada da figura autoral como demiurgo e protagonista da sua ficção.

Nesse espírito, em Escribas uma autora chamada A está tramando histórias de escribas mitológicas e históricas (até o século XIII). Paralelamente conta episódios de sua vida de maneira fragmentária e não cronológica. Nessas histórias, não falta um descenso ao inferno (protagonizada pela deusa Innana, na narração de Enheduanna) e uma defesa da caída como ascensão (Marguerite Porete com sua obra $O$ espelho das almas aniquiladas, ardendo na fogueira).

No livro Andante, que atualmente escrevo, Eurídice está explícita em um poema, "Assim falou Eurídice", e de maneira alusiva em outros dois: "Descenso" e "Pergunta". Ademais, de forma tangencial, em "Para Gwendolyn" que retoma o tema do descenso às regiões infernais, nesta ocasião inspirado no imaginário de 
Gwendolyn MacEwen ${ }^{7}$, escritora de fascinantes versões míticas, com a qual dialoga Margaret Atwood.

O inferno, âmbito principal na história de Eurídice e Orfeu, está presente nesses poemas com variadas formas. Pensando com Juan-Eduardo Cirlot (1992, p. 251), cabe salientar que é uma ideia de valor mítico constante, muito ativa na cultura, primeiramente concebido como forma de "subvida" (vida larvada dos mortos no seio da terra), depois lugar de tormentos. Instigante resulta o ponto de vista de R. M. Rosado Fernández, quando diz: "O mundo subterrâneo, com todo o sortilégio que lhe confere o misterioso desconhecido, com a força ctónica que lhe é peculiar, apresenta-se aos antigos como um reino onde a verdade pode ser encontrada ou, pelo menos, ouvida, porque as almas dos que desapareceram da terra a podem contar mais livremente" (1993: p. 347).

Seja nos repertórios clássicos ${ }^{8}$ ou cristãos, a descida ao inferno representa uma experiência de perdição e salvação, de revelação e ocultamento, de silencio e fala. Seus extremos, mais que polaridades em confronto, supõem intervalos desafiantes e fecundos.

Nas descidas a esse mundo subterrâneo, diversos imaginários vão se amalgamando até constituir um espaço de busca, autoconhecimento e transformação, como acontece no modelo da anábase clássica. Pela sua parte, a catábase forma uma ampla rede hipertextual não só referida ao mito de Orfeu e Eurídice. Na minha escritura essa viagem fantástica aparece freqüentemente, tanto no diálogo intertextual com a Divina Comédia, de Dante Alighieri, através das figuras de Francesca e Paolo, como com Uma temporada no inferno de Arthur Rimbaud.

O Inferno do Jardim das delícias, de Hieronymus Bosch, é o fio que trama Visiones de mujer con alas (2016), livro que tematiza uma descida ao inferno pessoal como espaço de memória e de renascimento, reinterpretando catábase e anábase em uma viagem de morte e vida, no qual o sujeito poético Narcisa, consubstanciada com a sombra, finalmente alcança sua luz. Neste mundo simbólico de ambigüidade e ambivalência, descenso e ascensão se correspondem em uma concepção que deve muito ao vazio pleno de Marguerite Porete, precursora no ocidente do misticismo negativo, embora de mais antiga existência noutras formas de espiritualidade como sufismo, taoísmo, budismo. 
No seio dessas versões heterodoxas, ao dizer de Cirlot, também resulta muito expressivo William Blake, quem desenvolve sua concepção em As bodas do céu e o inferno. Em sua visão o inferno é crisol das energias cósmicas, enquanto o céu simboliza a serenidade, a paz dos resultados últimos e a possibilidade de uma síntese (1992, p. 51).

Nesse âmbito tão rico dos motivos míticos recontados, brilha a poesia de Sophia de Mello Breyner Andresen vinculada a Eurídice ${ }^{9}$, motivo que tem manifesta centralidade em sua obra de grande riqueza imagética e conceitual. Nesse corpus - que atualmente leio e sobre o qual ainda não escrevi-, chamam a atenção as notáveis subversões de cânone: Eurídice é quem anda em busca de Orfeu, o inferno está recodificado - acaso o vasto mar incognoscível a mais poderosa -, a catábase está mais perto de imersão (talvez pela imagem do mar) que do descenso ao mundo subterrâneo.

Eros e Thanatos se fazem patentes na configuração dos amantes, mas de maneira nada convencional. A morte não é término, mas verdadeiro caminho para a completude no amor esférico do mito platônico, inalcançável no mundo dos vivos. Orfeu pretende a Eurídice na vida, não quer morrer; entretanto Eurídice o completa desde o reino da morte. Não só Orfeu, também Eurídice é uma configuração simbólica da poesia. Os dois poetas se espelham. E sobre todo este universo paira a memória com seu poder criativo.

Essa vastíssima rede de interpretações mostra a constância do tema de Eurídice no inferno e na luz, com notáveis variações, pois ainda que referido á narrativa mítica canônica, resulta subversivo. Eurídice torna-se sujeito principal da história e de sua trama. É configurada na sua identidade profunda de múltiplas fases, prismática e proliferante. Assim, a escolha do conceito de variação para estas notas responde à intenção de pensar as formas compositivas da semiose, tanto referidas na trama, como metafóricas e simbólicas. Suas motivações, conscientes ou subliminais, também estão no fundamento de um projeto ficcional pessoal em desenvolvimento.

Variação, como sabermos, é um termo que vem da música barroca com sua polifonia, contemporaneamente o jazz, uma de suas expressões mais elaboradas. No esclarecido verbete sobre Variações, Zilá Bernd refere suas estratégias, improvisação, repetição, proliferação, que caracterizam uma estética de movimento, de instabilidade e, sobretudo, de insubordinação à partitura (2010: p. 389). Desde a perspectiva da poética 
enfatiza suas possibilidades artísticas "metaforizando a mobilidade e a insubmissão como soluções literárias e também existenciais” (BERND, 2010: 401).

Nos poemas contemporâneos sobre Eurídice, a variação desenvolve uma metáfora seminal referida à possibilidade de transformação na busca de formas cada vez mais autoconscientes de identidade. Narrativiza, ademais, um processo de variados sentidos e potencialidades, inclusivo da alteridade, no qual a insubmissão se faz patente. Ficam na berlinda a sociedade patriarcal, suas performances de gênero, a invisibilidade e o silêncio impostos à mulher pelos costumes, modos, concepções e práticas de uma época que está durando milênios.

A Eurídice figurada, na esteira dos atos liberadores tão característicos da poesia de autoria feminina atual, tem suas próprias maneiras de libertação das imposições sociais que a desvanecem, deixam sim voz nem corpo e condenam à marginalidade. A Eurídice que se faz presente quer realizar uma vocação desalienante, para assumir sua criatividade como fazedora de si mesma que deixa seu legado no mundo da vida. Com outras formas, regressa, está aqui com um poder vivificador desconhecido.

Nos poemas de minha autoria, que surgiram na interação de escritura reflexiva e escritura de ficção, sua voz ganha realidade, seu corpo torna-se sonoro. Olho-me nela: espelho, reflexo, especulação. A Eurídice que me habita é, acima de tudo, uma figura do amor atuante, capaz de obrar na compaixão sem fim. Nela está a semente de Antígona que, na versão de Sófocles, nasceu para compartilhar amor, não ódio. A essa linhagem, nem tão comum no panteão ático, pertence à Eurídice que deixa partir ao amado e auspicia sua ascensão. A Eurídice que volta do desterro trazendo para Orfeu dilacerado umas romãs prodigiosas de seu jardim vital.

No seu conjunto os poemas interpretam variações sobre o tema de Eurídice, vinculados aos motivos de catábase e anábase, alguns de modo explícito, outros de forma indireta, mais velada. Neles a paixão de Eurídice está no mundo dos conflitos extremos. Então, nem tudo poderá ser entrega e amor. Sua cabeça foi roubada. Depara-se com morte, violência, desaparição. Mas é uma mulher errante, livre e ousada, que amou e foi amada, mas também perdida, deixada atrás, no inferno, onde longe de desvanecer, se refaz e transcende. Com consciência de si, exerce sua obra de fidelidade e perseverança. $\mathrm{Na}$ 
subversão do rol do herói mítico, desce ao inferno e desafia o poder da morte. Semelhante a Isis, dá ao corpo desmembrado do amado, uma nova forma imortal porque tem muita fé. Finalmente realiza um nosto, motivo caro á tradição clássica. Seu regresso é obra de “Amor constante, além da morte”, lembrando o ímpar soneto de Francisco de Quevedo, séculos depois magistralmente reinterpretado por Carlos Fuentes em Aura. O amor é possibilidade infinita que faz acontecer o impossível.

Hoje reconheço Eurídice como caminho possível e desejável. Sua imagem cheia de nuances, perto do "coração selvagem", me incita a procurá-la nas variações, formas fluidas, insubmissas, em movimento. Ela tem cabeça própria, sua busca não tem fim, assim como a palavra que a testemunha. O simbolismo de história mítica ganha literalidade, funciona a modo de efeito de distanciamento que permite a fala do não falado e abre as portas da intimidade inconfessa. Com Eurídice é possível traspassar o umbral, deixar atrás o reino da dor e a perda, tornando visíveis e interpretáveis fragmentos de vida na ficção. Com ela vamos ao encontro de nós mesmos e do Outro noutra altura da experiência vital.

A seguir os poemas, retomando a pergunta inicial para a qual não tenho uma resposta única, só estes textos abertos à interpretação.

\section{Poemas}

\section{Despedida de Eurídice}

acepto decirte adiós te despido en este lugar estático de la noche donde daré vida a los signos favorables de tu ascenso

oculto en los espejos negros sabrás que irás solo acompañado de augurios y de rumores delicados porque tu lugar es el eco 
y al despedirnos

me nombrarás

para que sea imagen

y las palabras del amor

sin tiempo

amor te deja partir

\section{Así habló Eurídice}

You hold love in your hand, a red seed you had forgotten you were holding.

Margaret Atwood

Estoy de vuelta del olvido

mi amor fue fiel en el destierro.

Estoy en tu memoria nítida

porque fui tu otro yo verdadero.

Cuando me perdiste en el infierno

después de tanto andar sin rumbo

en el umbral de la desmemoria

me acogí a mi sombra desolada.

Guardé las señales del tiempo

aprendí el placer de ser intacta

vestí las sutiles ropas del silencio

y las sandalias aladas de la muerte.

Por fin he vuelto con otra forma.

Mariposa negra en jubiloso duelo

innumerable semilla al viento.

Y como sé que estás dilacerado te traigo estas granadas milagrosas

de mi constante jardín del fuego. 


\section{Al partir}

como niebla

deslizas el rumor

de tus breves alas

amante

te contemplo

al volcarte

en lo que escapa

como en el ser

inasible de los sueños

te deshaces

hasta volverte

un punto esfumado

que viaja

en las palabras

si el vuelo

fuera designio

la línea de fuga

trazaría el perfil

melancólico de tu falta

sin haber llegado

te veo de ti partir

infinito al abrir las alas

\section{Descenso}

Ando en busca del Amado que tiene todas las formas duración inmortal y eco.

Pero la muerte nos antecede.

Allí en su fondo está él perdido amor sin cuerpo.

Cada noche lo invoco y trasmutado en sombra entre aromas resplandece.

Cálida ola del viento túrgida agua que en mí abre cauces inéditos. 
Hasta él desciendo

y en la vida lo acojo

para el amor sin muerte.

\section{En el camino}

\section{El verdadero camino es la caída \\ Marguerite Porete}

La partida es regreso.

Desnuda desciendo.

Me deshago de las formas

que me fijaron ausente.

Las memorias verdaderas

recupero en el olvido.

Y la sombra va conmigo.

Al viaje iniciático

me entrego.

Arrojo uno a uno

mis pedazos.

Hacia la otra margen

anonadada camino.

Ya mi alma vive

dentro del amor

libre de mí.

Nada en este mundo

me separa

de lo que amo.

La caída es ascenso. 


\section{Para Gwendolyn}

For years I have wanted to write a poem called

The Garden of the Thieves.

Gwendolyn MacEwen

Descendí hasta lo más profundo

en las tibias aguas de la sombra.

Era un jardín de ojos florecido

con sinuosos pinos oscilantes

y llamas de corales que ardían.

En el umbral estaba el Ladrón

que invocaba al destino

y entre sus manos mi cabeza

de ilusa medusa decapitada

sangrando en un plato.

Esperanzado el cuerpo

que sin entender sonreía

buscaba a tientas su cabeza

y al encontrarla con gozo

se la encajó de nuevo.

En el espejo de fluidas aguas

me vi libre mujer errante

que se corona a sí misma.

Y ahora finalmente entera

te cuento esta historia feliz

de la cabeza recobrada

en el jardín prodigioso.

\section{Mitológicas}

Las Ménades del goce

posesivo privadas

con furia lo despedazan

y hunden su lírica cabeza

en el río helado de la muerte.

Isis apasionada lo busca

unge sus pedazos devota

en oro crea su falo delicioso 
con mucha fe bate las alas

$\mathrm{y}$ amante lo resucita.

En toda historia

entre la furia y la fe

el amor es forma.

\section{Isis rosa}

Es dos alas infinitas

que se despliegan suntuosas

engarzadas en un tallo.

No es más que esas dos alas.

Su rostro a cada vuelta renace.

Sabe que eros y tanatos

son de lo mismo fases.

Madre de fallecidos y vivos

va juntando los pedazos

y cuando agita sus alas

el cuerpo desmembrado

en el amor rehace.

Después de la ilusoria vida

habita la casa real

de la vida verdadera.

\section{Pregunta}

Todavía me pregunto

si cuando ellas

enloquecidas

lo dilaceraron

y a las aguas

de la desmemoria

sin lira

sin voz

sin sexo

lo arrojaron

¿fue venganza o justicia

por en el infierno

haberla dejado? 


\title{
Otro infierno
}

\author{
Pero siempre solo; sin familia; \\ hasta esto, ¿qué lengua hablaba? \\ Arthur Rimbaud
}

Estuve una temporada

en el infierno no de Dante

que era fabuloso imaginario.

Mi infierno tenía la forma

del lugar común del yo.

Descendí a los círculos

apenas tristes laberintos

sin salida semejantes al caos.

Erré en lo profundo

preguntando absurdos

procurando claves.

Aullé de esclarecido miedo.

Y de tanto vagar y sufrir y gritar quedé sanamente enferma y muda que no del todo y al fin muerta.

De vuelta al mundo de los vivos

recupero la tenue luz del anochecer

la bondad del café en la mañana

el aire sutil de la alta noche

las buenas conversas a solas conmigo.

Y dejo correr las horas vagas

mirando el ir y venir de las nubes

que impasibles van hacia la nada.

Ausculto mi cuerpo y escucho

el ritmo acompasado del día

con sus esclarecidos meandros.

Ahora sé que cada paso es camino.

Toco la vida y todo alcanza

sentidos inagotables.

Estoy en paz.

Y sueño. 


\section{Referências}

CIRLOT, Juan-Eduardo. Infierno. Diccionario de símbolos. Barcelona: Editorial Labor, 1992.

BARTHES, Roland. Mitologías. México: Siglo XXI, 1980.

BERND, Zilá. Variações. In: BERND, Zilá (org.). Dicionário das mobilidades culturais: percursos americanos. Porto Alegre: Literalis, 2010. p. 389-404..

BOLAÑOS, Aimée G. Eurídice segundo Atwood? Interfaces Brasil/Canadá, v. 4, no. 1 2004, p. 27-44.

- Poesía insular de signo infinito: una lectura de poeta cubanas de la diáspora. Madrid: Betania, 2007.

. Las palabras viajeras. Madrid: Betania, 2013.

. Escribas. Madrid: Betania, 2013.

. Visiones de mujer con alas. Madrid: Betania, 2017.

BOLAÑOS, Aimée G.; HAZELTON, Hugh. Gwendolyn MacEwen: versiones de su poesía. Interfaces Brasil/Canadá, no. 3, v.17, 2017, p. 155-171.

FERNANDES, R. M. Rosado. Catábase ou descida aos infernos. Alguns exemplos literários. Hvmanitas, v. XLV, 1995, p. 347-350.

FERREIRA, José Ribeiro. O tema de Orfeu em Musa de Sophia de Mello Breyner Andresen. Hvmanitas, v. L, 1998, p. 1019-1024.

LUCIFORA, María Clara. Las autopoéticas como máscaras. RECOAL, n. 7, s.p., 2015.

MORAES, Vinicius de. Orfeu da Conceição (Tragedia carioca). Rio de Janeiro: Editôra Dois Amigos, 1956.

PEREIRA, Maria Helena da Rocha. Motivos clássicos na poesia portuguesa contemporânea: O mito de Orpheu e Eurídice. Novos ensaios sobre temas clássicos na poesia portuguesa, Lisboa, Imprensa Nacional-Casa da Moeda, 1988, p. 303-322.

RICOEUR, Paul. Sí mismo como otro. Madrid: Siglo XXI, 1996.

. Del texto a la acción. México D.F.: Fondo de Cultura Económica, 2001.

ROSADO, R. M. Fernández. Cátabe ou descida aos infernos. Alguns exemplos literários. Hvmanitas, v. XLV, 1993, p. 348-359.

SANTOS, Elaine Cristina Prado dos. A catábase: a descida aos infernos, segundo a visão de Vergílio, de M. Camus e de V. Ward. Tessituras, Interações, Convergências. XI Congresso Internacional da ABRALIC, 2008. Disponível em: https://abralic.org.br/ eventos/cong2008/AnaisOnline/simposios/pdf/013/ELAINE_SANTOS.pdf. Acesso em: 2 de dezembro 2010. 
SCARANO, Laura. Escribo que escribo: de la metapoesía a las autopoéticas. Tropelías, n. 2, p. 133-152, 2017.

\section{Notas}

* Nota: Os poemas "Despedida de Eurídice" e "Al partir" pertencem a Las palabras viajeras. "En el camino", "Otro infierno", "Isis rosa" estão em Visiones de mujer con alas. Fazem parte do livro em processo Andante: "Así habló Eurídice", "Descenso", "Pregunta", "Mitológicas" e "Para Gwendolyn".

1 Professora do Programa de Pós-Graduação em Letras da Universidade Federal do Rio Grande (FURG), Rio Grande do Sul, Brasil. Professora adjunta da Universidade de Ottawa, Canadá. aimee@vetorial.net.

2 Dentre as tantas versões no mundo clássico, e posteriormente, a continuação transcrevo o resumo do mito realizado por Elaine Cristina Prado dos Santos no seu artigo sobre catábase (2008) a partir da versão de Vírgilio no canto IV das Geórgicas: "Orfeu, desesperado pela morte da esposa Eurídice, desceu aos Infernos para trazê-la de volta à vida. A dor de Orfeu foi tanta que resolveu arrancar a esposa à morte, já que, sem ela, não conseguiria viver. Por meio do som inebriante de sua lira e de sua divina voz, Orfeu encantou o mundo ctônico, comovendo Caronte, que largou o barco e seguiu o cantor. Comovidos com a voz de Orfeu e com tamanha prova de amor, Plutão e Prosérpina - os deuses infernais - concordaram em devolver-lhe a esposa, entretanto uma condição foi imposta: ele iria à frente e ela lhe acompanharia os passos, mas Orfeu não poderia olhar para trás. Os dois amantes subiam em direção à luz, na dura estrada que conduzia da morte à vida, mas ele não resistiu, olhou para trás e viu Eurídice sumir para sempre em uma sombra. Orfeu tentou regressar, mas não foi the dada uma segunda chance. Inconsolável e fiel a seu amor, Orfeu passou a repelir todas as mulheres da Trácia, que se sentiram desprezadas, mataram-no e esquartejaram-no e lançaram-lhe os restos e a cabeça no rio Hebro. Ao rolar a cabeça no rio, sua boca proferiu o nome de Eurídice."

3 Ver Eurídice segundo Atwood? Interfaces Brasil/Canadá, v. 4, no. 1, 2004, p. 27-44.

4 Interpretaciones de Eurídice. Poesía insular de signo Infinito. Una lectura de poetas cubanas da diáspora. Madrid: Betania, 2007, p. 61-88. O livro é resultado de um pós-doutorado orientado por Zilá Bernd na Universidade Federal de Rio Grande do Sul; também integra o trabalho investigativo realizado na Université du Québec à Montréal, em diálogo com Simon Harel.

5 O conceito de autopoética, segundo María Clara Lucifora (2015) supõe uma postulação do programa de escritura, em textos reflexivos ou ficcionais. Dota o escritor de uma identidade ao criar um espaço privilegiado para a construção de sua figura autoral. Na visão de Laura Scarano (2017), a autopoética (mais que o termo muito geral de poética) oferece valiosas pautas epistemológicas e metodológicas para o entendimento da função-autor. Mais que justificativa, implica a proclamação de pressupostos estéticos, espécie de projeto autoral explícito que focaliza o "si mesmo" nas diversas operações autorreferenciais.

6 Vale lembrar que catábase, ação de descer, descida ao mundo subterrâneo, mundo inferior, mundo dos mortos, geralmente inferno, é um topos da literatura antiga, presente na tradição mesopotâmica, egípcia e greco-latina. Anábase, subida, ascensão á luz, foi consagrado pela obra de Xenofonte Retirada dos Dez Mil. Ambos os motivos tem longa vida literária e artística. A catábase, experiência de morte, vincula-se á anábase. Integram gradativamente anagnórise, autoconhecimento, transformação.

7 Ver: BOLAÑOS, Aimée G.; HAZELTON, Hugh. Gwendolyn MacEwen: versiones de su poesía. Interfaces Brasil/Canadá, no. 3, v.17, 2017, p. 155-171.

8 "Segundo a literatura clássica, em Homero, o Hades é um imenso abismo, onde as almas são lançadas para todo o sempre; em Hesíodo, já existia uma mudança escatológica no destino de algumas almas privilegiadas; no entanto, o Orfismo fixou normas topográficas definidas e reestruturou o destino das almas. Oficialmente, o Hades foi dividido em três regiões distintas: a parte mais profunda, o Tártaro; a medial, o Érebo e a mais alta e nobre, os Campos Elísios. Enquanto os dois primeiros eram destinados aos tormentos impostos às almas, os Campos Elísios seriam para aqueles que tinham passado pelos horrores dos dois outros compartimentos e iriam retornar à vida." (DOS SANTOS, 2008: s/p)

9 Três poemas titulados "Eurydice", "Soneto a Eurydíce", “A Praia Lisa","Orpheu", "Orpheu e Eurydice", "Eurydice em Roma" e "Elegia". Ver: O tema de Orfeu em Musa de Sophia de Mello Breyner Andesen (FERREIRA, 1998) 